\title{
The Effect of Curing Conditions on the Properties of Cement- Based Composites Blended with Waste Marble Dust
}

\author{
NADHIR TOUBAL SEGHIR, ${ }^{1,4}$ MEKKI MELLAS,,${ }^{1,5}$ \\ LUKASZ SADOWSKI $\odot,{ }^{2,6}$ ALEKSANDRA KROLICKA, ${ }^{3,7}$ \\ and ANDRZEJ ŻAK ${ }^{3,8}$ \\ 1.-Civil Engineering Research Laboratory, Biskra University, 07000 Biskra, Algeria. 2.—Faculty \\ of Civil Engineering, Wroclaw University of Science and Technology, Wybrzeze Wyspianskiego 27, \\ 50-370 Wrocław, Poland. 3.-Faculty of Mechanical Engineering, Wroclaw University of Science \\ and Technology, Wybrzeze Wyspianskiego 27, 50-370 Wrocław, Poland. 4.-e-mail: \\ tsnadhir@gmail.com. 5.—e-mail: m_mellas@yahoo.fr. 6.—e-mail: lukasz.sadowski@pwr.edu.pl. \\ 7.—e-mail: aleksandra.krolicka@pwr.edu.pl. 8.—e-mail: andrzej.zak@pwr.edu.pl
}

The goal of this article is to study the effect of curing conditions on the properties of cement-based composites blended with waste marble dust (WMD). WMD was added to cement-based composites with different ratios of replacement, and two of the most commonly used curing conditions were applied. Half of the composites were cured in water at a temperature of $20 \pm 1^{\circ} \mathrm{C}$, and the other half of the composites were cured in air at a temperature equal to $22 \pm 2^{\circ} \mathrm{C}$ and relative humidity (RH) equal to $20 \pm 1 \%$. To achieve the goals of the study, the composites were tested after 3 days, 7 days, 28 days, and 65 days of curing for their apparent density $\left(\Upsilon_{\mathrm{ad}}\right)$, porosity $\left(p_{\mathrm{m}}\right)$ and compressive strength $\left(f_{\text {cd }}\right)$. Finally, the obtained macroscopic observations were validated using scanning electron microscopy. It was found that the water curing conditions were beneficial for the cement-based composites and gave satisfactory results compared with the air-curing conditions.

\section{INTRODUCTION}

It is commonly known that the hardening process and formation of the microstructure of cementbased composites are significantly influenced by the curing conditions. ${ }^{1}$ Curing conditions applied in a laboratory vary from those applied on a real construction site. In a laboratory, composites are usually immersed in water for curing, whereas on a construction site, composites cure mostly in air conditions. These two methods of curing are most commonly used for cement-based composites. The curing conditions result in different final properties of hardened cement-based composites.

Several studies have recently been conducted on the influence of different curing conditions on the properties of cement-based composites. ${ }^{2-4}$ Most of them proved that curing conditions, curing time ${ }^{5}$ and the curing period influenced the development of the properties of cement-based composites. ${ }^{6}$ For example, Bingöl and Tohumcu ${ }^{7}$ found that aircuring conditions caused a loss in the compressive strength of self-compacting concrete (SCC) blended with fly ash (FA) and silica fume compared with water-curing conditions. Moreover, Poon et al. ${ }^{8}$ proved that cement-based composites blended with FA cured in water at $27^{\circ} \mathrm{C}$ had higher compressive strength and lower porosity compared with those cured in air at $15^{\circ} \mathrm{C}$ and at $60 \%$ relative humidity (RH). Aldea et al. ${ }^{9}$ specified that curing at $80^{\circ} \mathrm{C}$ is preferable to normal curing at $20^{\circ} \mathrm{C}$ and $100 \% \mathrm{RH}$ for cement-based composites blended with slag. ${ }^{10}$ The curing temperature also affects the compressive strength of cement-based composites blended with high phosphorous slag, ${ }^{11}$ calcium aluminate, ${ }^{12}$ biomass ashes ${ }^{13}$ and geothermal silica waste. ${ }^{14}$ In study, ${ }^{15}$ ordinary curing $\left(20 \pm 1^{\circ} \mathrm{C}\right)$ was beneficial for cement-based composites blended with metakaolin. Generally, the curing conditions affected the development of the properties of ordinary cementbased composites, ${ }^{16}$ composites modified by fly ash, ${ }^{17}$ composites modified by recycled aggregates $^{18,19}$ and a composite's long-term compressive strength. ${ }^{20}$ This was also the case under hot 
weather conditions. ${ }^{21}$ Of note, high air temperature and low humidity caused water to evaporate from a fresh cement-based mixture in a mold. ${ }^{7}$ Watercuring conditions can effectively reduce this problem, ${ }^{16}$ as is also the case in cement-based composites with mineral admixtures. ${ }^{22}$ Salhi et al. ${ }^{23}$ reported that an increase of temperature and decrease of humidity increase the evaporation rate in SCC. The strong influence of curing conditions on concrete is due to the effect of these conditions on the hydration degree of cement, especially belite $\left(\mathrm{C}_{2} \mathrm{~S}\right){ }^{22}$ As pointed out by Rizzo et al. ${ }^{24}$ the durability and strength of concrete may deviate from the design conditions as a result of accidental factors such as inappropriate curing due to changes of the water-cement ratio.

Cement-based composites have recently been more frequently blended with mineral admixtures. Admixtures with particles similar to those in cement-based composites are especially useful for this purpose. ${ }^{25}$ They are usually termed dusts (also called powders, ashes, etc.). These dusts are more commonly sourced from industrial wastes, e.g., from the production of aggregates in aggregate quarries. ${ }^{26}$ The proper disposal of these waste quarry dusts has recently become a serious ecologic problem. It has been proved in the literature that waste marble dust (WMD) is suitable to replace some of the cement in cement-based composites, such as the cement paste, mortar and concrete. However, as highlighted previously in, Ref. 27 studies related to WMD have mostly been performed on concrete and mortar composites cured in water. Thus, our previous study ${ }^{27}$ proved that the incorporation of WMD in air-cured cement paste is beneficial. Attempts to replace some parts of cement using industrial byproducts, such as WMD, have recently been successfully performed. ${ }^{28-35}$ The proper utilization of WMD is a thoughtful large-scale ecologic problem. ${ }^{36-41}$

Many studies have been carried out to determine the physical and chemical properties of cementbased composites blended with WMD. ${ }^{42-44}$ It has been proved in the literature that the application of WMD improves the fresh properties of SCC, $39,45-48$ colored SCC, ${ }^{49}$ self-compacting mortar, ${ }^{47,48}$ ordinary $^{31}$ and adhesive ${ }^{50}$ mortars, the compressive strength of mortar ${ }^{31,51-53}$ and the durability of concrete. ${ }^{54}$ WMD has also recently been used by Colangelo et al. ${ }^{55}$ as an inert filler to reduce drying shrinkage of lightweight geopolymer composites. As reported in the literature, the use of WMD as a cement replacement in an amount of up to $10 \%$ of the mass of the binder improves the properties of mortar and concrete cured in water conditions. This may be due to the effect of the micro-filler present in WMD, which helps to form a dense mix by filling voids. ${ }^{51}$ In addition, it may also be due to an increase of the total volume of hydration products, ${ }^{56}$ which is the result of the reaction between calcium carbonate $\left(\mathrm{CaCO}_{3}\right)$ and tricalcium aluminate
$\left(\mathrm{C}_{3} \mathrm{~A}\right) \cdot{ }^{27,32,37,41}$ After analyzing examples from the literature, it can be seen that ordinary water-curing conditions at a temperature equal to $20 \hat{\mathrm{A}}^{\circ} \mathrm{C}$ are best for curing cement-based composites blended with WMD.

However, to the best of our knowledge there are no studies on the effect of curing conditions on the properties of cement-based composites blended with WMD, which is used as a partial replacement of cement. When considering the above, the article aims to investigate the effect of different curing conditions after 3 days, 7 days, 28 days, and 65 days (water cured at a water temperature equal to $20 \pm 1^{\circ} \mathrm{C}$ and air cured at an air temperature equal to $22 \pm 2^{\circ} \mathrm{C}$ and relative humidity of $20 \pm 1 \%$ ) on the properties of cement-based composites blended with WMD. This was achieved by determining the compressive strength, apparent density and porosity. In addition, scanning electron microscopy (SEM) analysis was also performed on the specimens after 28 days of being cured in these two different conditions.

\section{MATERIALS AND METHODS}

\section{Materials}

The investigated cement-based composite is composed of ordinary Portland cement (OPC) and tap water and it is blended with WMD.

Biskria Ciment ${ }^{57}$ provided the OPC type CEM I $42.5 \mathrm{R}$. The WMD was obtained in the form of an aggregate from CHATT/Fil-Fila quarry. ${ }^{58}$ Because it is a challenge to transform industrial wastes into a raw material, ${ }^{59}$ to obtain a fineness close to OPC, the WMD was ground using a classic line grinder (Fig. 1).

\section{Test Procedure}

A D8 ADVANCE x-ray powder diffractometer and Zetium x-ray fluorescence spectrometry were used to determine the mineralogic and chemical compositions of the cement-based composites. The Bogue equation was used. ${ }^{60}$ The different setups for the preparation of the WMD and the methodology of the experimental program are presented in Fig. 1. The physical characteristics of OPC and WMD are presented in Table I and Fig. 2a. The particle size distribution (PSD) was determined using a Malvern Mastersizer 2000 analyzer. Moreover, the chemical and mineralogic characteristics are presented in Fig. 2b.

Initially (from the time of casting until demolding), all the specimens (only the top surface) were packed so that the water would not evaporate and then put to cure in standard laboratory conditions at $22 \pm 2{ }^{\circ} \mathrm{C}$ and more than $20 \pm 1 \% \mathrm{RH}$. After demolding (about $24 \mathrm{~h}$ ), the specimens were divided into two groups-water cured at $20 \pm 1^{\circ} \mathrm{C}$ and air cured at $22 \pm 2^{\circ} \mathrm{C}$. Different tests were performed at 3 days, 7 days, 28 days, and 65 days to verify the 


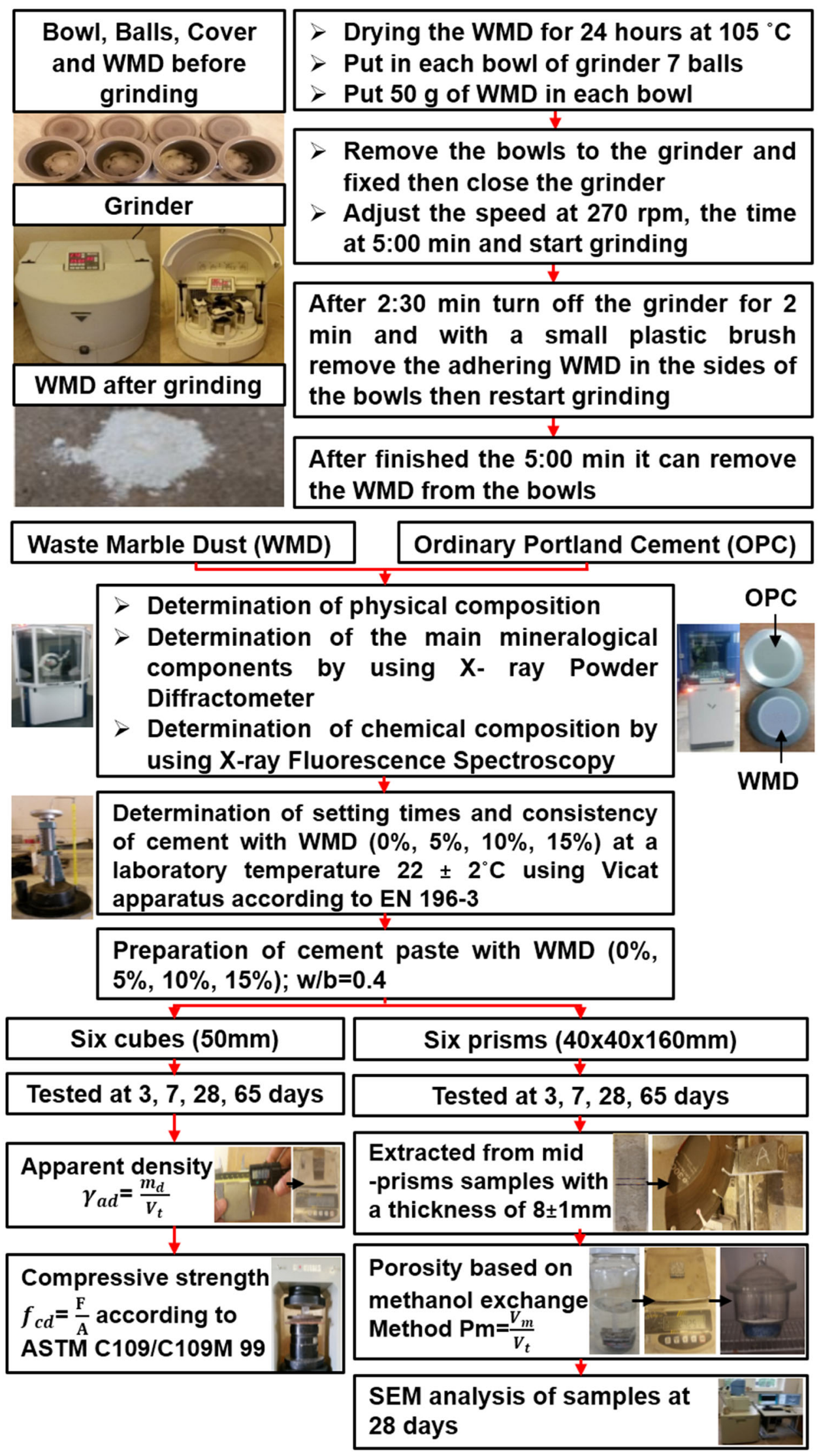

Fig. 1. Methodology of experimental setup. 
The Effect of Curing Conditions on the Properties of Cement-Based Composites Blended

apparent density, compressive strength and porosity.

According to Kirgiz, ${ }^{61}$ the apparent density was determined using Eq. 1:

Table I. Physical properties of ordinary Portland cement (OPC) and waste marble dust (WMD)

\begin{tabular}{|c|c|c|}
\hline Physical properties & OPC & WMD after grinding \\
\hline Specific gravity $\left(\mathrm{g} / \mathrm{cm}^{3}\right)$ & 3.15 & 2.74 \\
\hline Bulk density $\left(\mathrm{g} / \mathrm{cm}^{3}\right)$ & 0.98 & 0.98 \\
\hline Blaine fineness $\left(\mathrm{cm}^{2} / \mathrm{g}\right)$ & 3571.78 & 3869.46 \\
\hline
\end{tabular}

$$
\gamma_{\mathrm{ad}}=\frac{m_{\mathrm{d}}}{V_{\mathrm{t}}}
$$

where $\gamma_{\mathrm{ad}}$ is the apparent density $\left(\mathrm{g} / \mathrm{cm}^{3}\right), m_{\mathrm{d}}$ is the mass of the dry specimen $(\mathrm{g})$, and $V_{\mathrm{t}}$ is the volume total of the specimen $\left(\mathrm{cm}^{3}\right)$.

The compressive strength was determined according to ASTM C 109/C 109 M $99^{62}$ using Eq. 2:

$$
f_{\text {cd }}=\frac{F}{A}
$$

where $f_{\text {cd }}$ is the compressive strength $(\mathrm{MPa}), F$ is the failure load (N), and $A$ is the loading area $\left(\mathrm{mm}^{2}\right)$. At first, it was necessary to measure the length, width and height for each specimen using a digital caliper and then estimate the weight using an

(a) -WMD after grinding —OPC —WMD before grinding
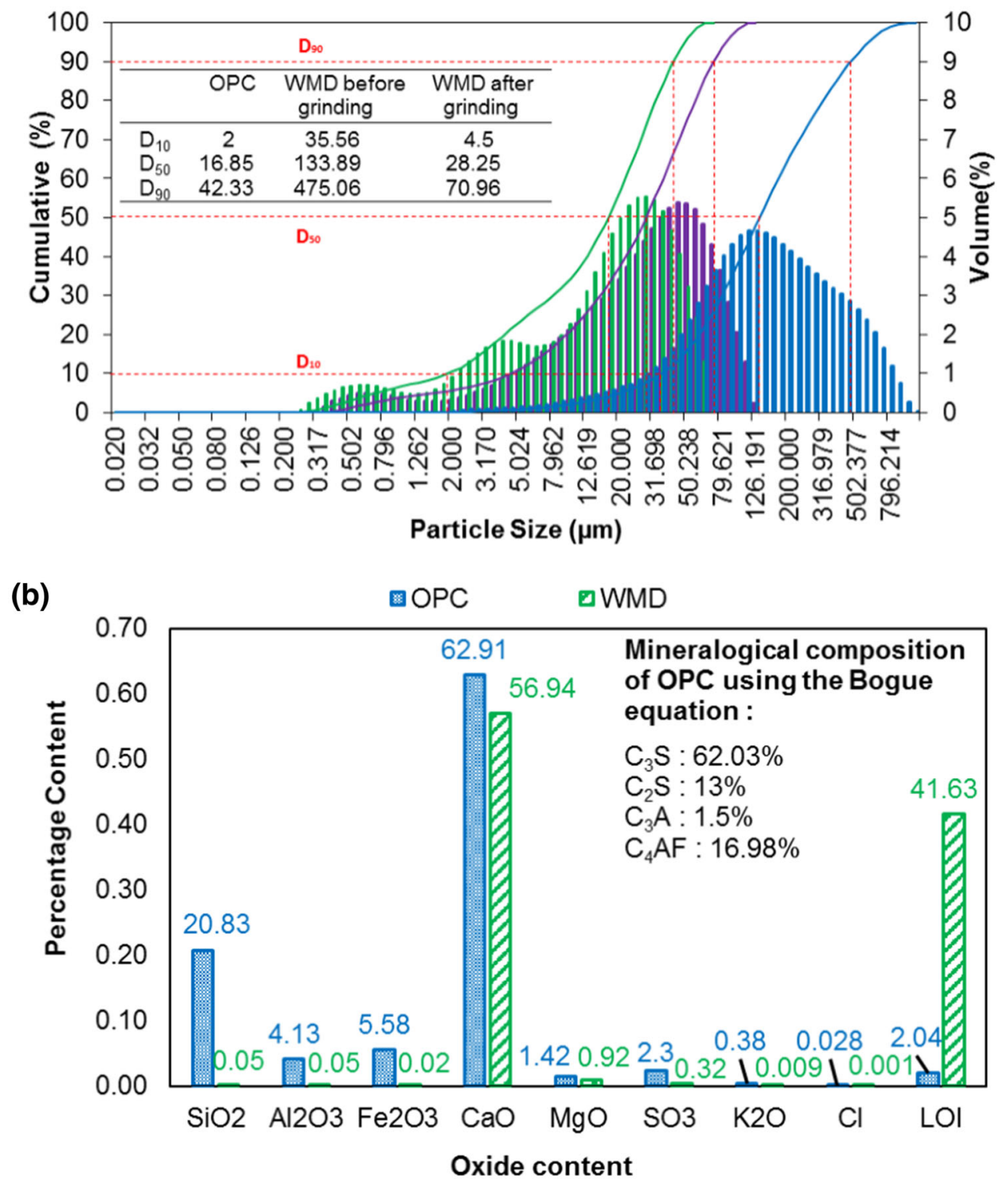

Fig. 2. Characteristics of ordinary Portland cement (OPC) and waste marble dust (WMD): (a) particle size distribution; (b) chemical and mineralogical composition. 
electronic balance (Fig. 1). The apparent density was then determined by dividing the mass of each specimen by its volume.

Next, after determining the apparent density, the specimen was put in a compressive machine (Fig. 1) with a maximum capacity of about $1000 \mathrm{KN}$ to obtain the failure load. The failure load of each specimen was divided by the loading area to calculate the value of the compressive strength.

For porosity, the methanol exchange method was used (Fig. 1). According to the procedure described in Refs. 63 and 64 prisms of $40 \times 40 \times 160 \mathrm{~mm}$ were cut in the middle to extract samples with a thickness of $8 \pm 1 \mathrm{~mm}$. They were then placed inside the methanol solution until reaching a constant weight at between 3 days, and 14 days. Thus, the methanol replaced all the water existing inside the samples. The samples were then dried over silica gel for $24 \mathrm{~h}$ at a temperature of $20^{\circ} \mathrm{C}$. Finally, the weight of each sample was estimated using an electronic balance, and the porosity was measured using the following formula:

$$
p_{\mathrm{m}}=\frac{V_{\mathrm{m}}}{V_{\mathrm{t}}}
$$

where $p_{\mathrm{m}}$ is the porosity based on the methanol exchange method (\%), $V_{\mathrm{m}}$ is the volume occupied by methanol in the samples $(\mathrm{g})$, and $V_{\mathrm{t}}$ is the total volume of the samples $\left(\mathrm{cm}^{3}\right)$.

The microstructure analysis was conducted on the specimens at 28 days using scanning electron microscopy methods. The microstructure of the samples was analyzed on their cross section to reduce the impact of surface defects. The significant porosity of the cement samples, compared with other engineering materials, causes them to adsorb a large amount of gas. For this reason, in highvacuum devices, including electron microscopes, the volume of the sample should be reduced to the necessary minimum. In the case of the described research process, the $10 \mathrm{~mm} \times 10 \mathrm{~mm} \times 10 \mathrm{~mm}$ sample was cut in the zone of interest using a precise diamond saw. The samples were then coldmounted in a two-component Epidian 5 epoxy resin with Z1 hardener (Ciech Sarzyna, Poland), wet sanded on abrasive papers graded at $120,320,600$, 800 and 1200, and then polished with mono-crystalline diamond suspensions with a granulation of $6 \mu \mathrm{m}$ and $1 \mu \mathrm{m}$. Tests of non-conductive materials using an electron beam require the electron drainage from the analyzed surface to be provided. Vacuum sputtering with graphite or metals such as gold, silver, chromium or aluminum is extensively used for this purpose. Because microanalysis of the chemical composition was planned, it was decided to cover the sample with a layer of carbon approximately $40 \mathrm{~nm}$ in a high vacuum evaporator (Edwards Vacuum, England).

The JEOL JSM-6610A scanning electron microscope was equipped with a conventional tungsten filament electron gun and was working on an accelerating voltage of $20 \mathrm{kV}$ that compromised the analytical performance and imaging resolution. The chemical element composition was determined using an energy-dispersed x-ray spectrometer (EDS, EDX) JEOL JED-2300. The count rate was set to approximately $7000 \mathrm{cps}$, and the detector dead time did not exceed 5\%. Quantitative analyses were performed using JEOL software and the integrated ZAF method. To obtain a visualization of the relative chemical composition distribution of the samples, elementary mappings were made. The data acquisition time was about $3 \mathrm{~h}$ for each analysis. The obtained intensity maps of the elements had a resolution of $512 \times 384$ points with the size of the observation field being $2.9 \times 2.2 \mathrm{~mm}$.

\section{CHARACTERISTICS OF RAW MATERIALS}

As seen in Table I and Fig. 2b, the Blaine fineness of the WMD equal to $3869.46 \mathrm{~cm}^{2} / \mathrm{g}$ is very close to that of the OPC (Blaine fineness of $3571.78 \mathrm{~cm}^{2} / \mathrm{g}$ ). There is one difference in the percentage of the size of the particles. For the OPC, the particles smaller than $45 \mu \mathrm{m}, 17 \mu \mathrm{m}$ and $3 \mu \mathrm{m}$ represent about $90 \%$, $50 \%$ and $10 \%$ of the total material volume, respectively. The particles less than $80 \mu \mathrm{m}, 30 \mu \mathrm{m}$ and $5 \mu \mathrm{m}$ in the WMD represent about $90 \%, 50 \%$ and $10 \%$ of the total material volume, respectively. On the other hand, both materials are characterized by a similar bulk density of about $0.98 \mathrm{~g} / \mathrm{cm}^{3}$.

The results obtained using the XRD and XRF showed the difference of the mineralogical and chemical compositions of the WMD and OPC. The OPC has four mineral components: tricalcium silicate $\left(\mathrm{C}_{3} \mathrm{~S}\right)$, dicalcium silicate $\left(\mathrm{C}_{2} \mathrm{~S}\right)$, tricalcium aluminate $\left(\mathrm{C}_{3} \mathrm{~A}\right)$ and tetracalcium aluminoferrite $\left(\mathrm{C}_{4} \mathrm{AF}\right)$ as well as gypsum $\left(\mathrm{CaSO}_{4} \cdot 2 \mathrm{H}_{2} \mathrm{O}\right){ }^{27}$ The WMD has two mineral components: $\mathrm{CaCO}_{3}$ as the main mineral and also dolomite $\left(\mathrm{CaCO}_{3} \cdot \mathrm{MgCO}_{3}\right)$. Similar characteristics were obtained by the authors of Refs. 27, 32, 35 and 38.

Figure $2 \mathrm{~b}$ also shows that the major component of OPC and WMD is calcium oxide $(\mathrm{CaO})$, with a proportion of $62.91 \%$ and $56.94 \%$, respectively. Compared with the OPC, the WMD has a lower amount of silicon dioxide $\left(\mathrm{SiO}_{2}\right)$, aluminum oxide $\left(\mathrm{Al}_{2} \mathrm{O}_{3}\right)$ and iron oxide $\left(\mathrm{Fe}_{2} \mathrm{O}_{3}\right)$. The WMD also has a higher loss on ignition (LOI) than the OPC. Similar characteristics were also obtained by Hamza et al. ${ }^{44}$

\section{BASIC PROPERTIES OF FRESH CEMENT PASTE}

In Fig. 3, the basic properties (consistency and setting time) of the fresh cement paste with and without WMD are presented. As seen in this figure, the use of WMD does not significantly affect the basic properties of the fresh cement pastes. According to EN 196-3, ${ }^{65}$ a Vicat needle was used to determine the setting time (initial and final) and the 


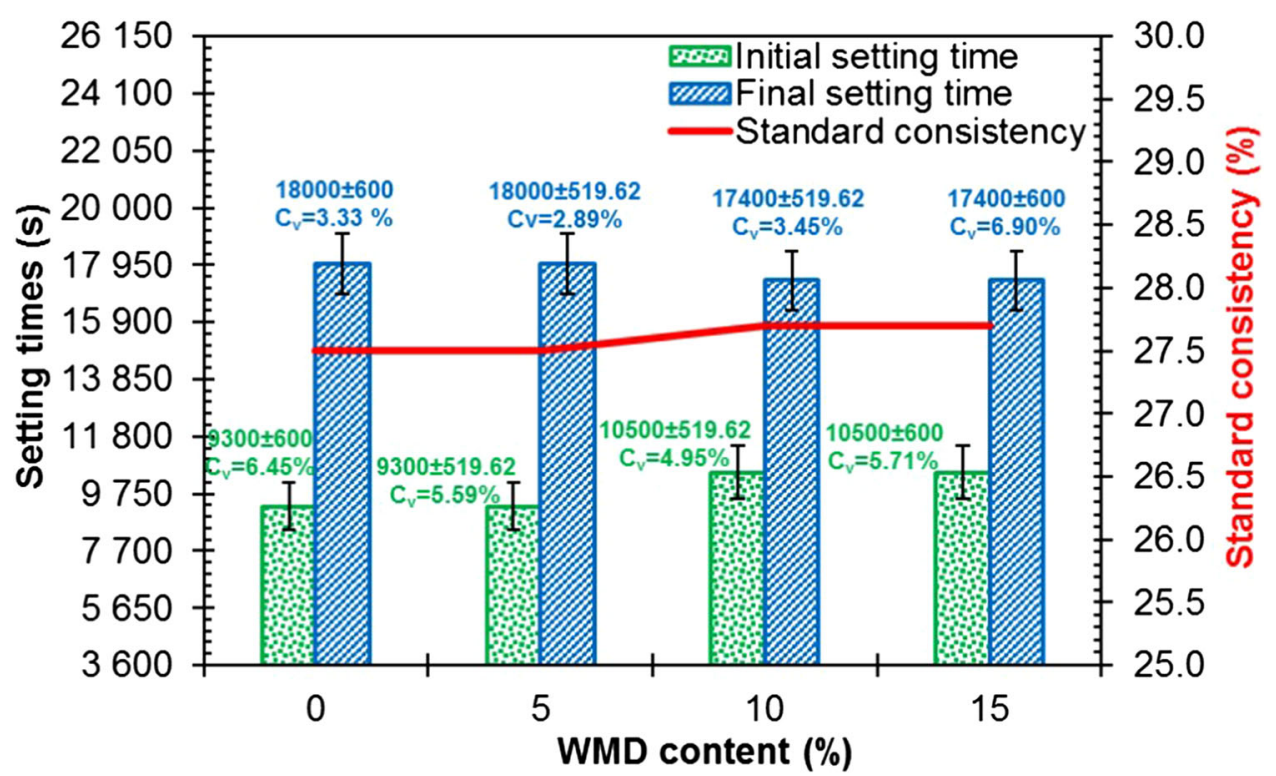

Fig. 3. Basic properties of fresh cement paste.

consistency. As previously pointed out by Toubal Seghir et al. ${ }^{27}$ this may be due to the similar fineness of the WMD and OPC.

\section{RESULTS AND DISCUSSION}

The apparent density $\left(\Upsilon_{\mathrm{ad}}\right)$, compressive strength $\left(f_{\text {cd }}\right)$ and porosity $\left(p_{\mathrm{m}}\right)$ of cement-based composites blended with WMD at different curing conditions and at different ages are presented in Fig. 4.

Figure $4 \mathrm{a}$ shows that the obtained $\Upsilon_{\mathrm{ad}}$ of the water-cured composites was higher than that obtained from the air-cured composites. This may be due to the lower volume of hydrate products for the cement hydration. In the case of the specimens cured in air, some of the water present in the composites evaporated. This may suggest that the compounds of the cement did not completely hydrate.

In both curing conditions, the $\Upsilon_{a d}$ slightly decreases when the WMD content increases in comparison to the control composite. This may be because the specific gravity of the WMD is lower than that of the OPC. ${ }^{27,56,66,67}$

The incorporation of WMD in an amount ranging from $5 \%$ to $15 \%$ of the mass of the binder causes a decrease of the $\Upsilon_{\mathrm{ad}}$ from $0.72 \%$ to $2.04 \%$ for the water-cured composites and from $1 \%$ to $2.80 \%$ for the air-cured composites.

Figure $4 \mathrm{~b}$ shows that the compressive strength $\left(f_{\text {cd }}\right)$ decreases with the increase of the WMD content. In addition, the water-cured specimens showed a higher $f_{\text {cd }}$ than the air-cured specimens. A similar observation was noticed by Poon et al. ${ }^{8}$ who used FA as a cement replacement.
In the case of water-cured conditions, the use of WMD in amounts of 5\%,10\% and $15 \%$ of the mass of the binder decreases the $f_{\text {cd }}$ compared with the control composite. These results are close to those found in the literature, ${ }^{56}$ where WMD was incorporated in amounts ranging from $10 \%$ to $40 \%$.

The decrease of the $f_{\mathrm{cd}}$ was attributed to the decrease of $\Upsilon_{\mathrm{ad}}$. This is possibly due to the significant reduction of $\mathrm{C}_{3} \mathrm{~S}$ and $\mathrm{C}_{2} \mathrm{~S}$ in the cement-based composite. $\mathrm{C}_{3} \mathrm{~S}$ and $\mathrm{C}_{2} \mathrm{~S}$ are mainly responsible for strength development. ${ }^{27,32,53,56,68}$

In the case of air-cured conditions, a decrease of $f_{\text {cd }}$ was also noticed. From these results, it can be stated that the water-cured composites with a content of $5 \%$ and $10 \%$ WMD of the mass of the binder showed a higher decrease of $f_{\text {cd }}$ than the aircured composites. For composites with a WMD content of $15 \%$ of the mass of the binder, the results of the air-cured composites showed a higher decrease of $f_{\text {cd }}$ than the water-cured specimens. However, the water-cured specimens have a higher $f_{\text {cd }}$ than the air-cured specimens. This may be due to the presence of the higher volume of hydrate products for the water-cured composites compared with the air-cured composites.

Figure $4 \mathrm{c}$ shows that the air-cured composites presented higher porosity $\left(p_{\mathrm{m}}\right)$ than the water-cured composites.

For water-cured conditions, the porosity decreases with an increase of WMD of up to $10 \%$ of the mass of the binder at all curing ages (Fig. 4c). This could be explained by the effect of this inert addition, because ultrafine aggregates fill voids. ${ }^{41} \mathrm{In}$ turn, a $15 \%$ level of WMD of the mass of the binder led to an increase in porosity at all curing ages. This 

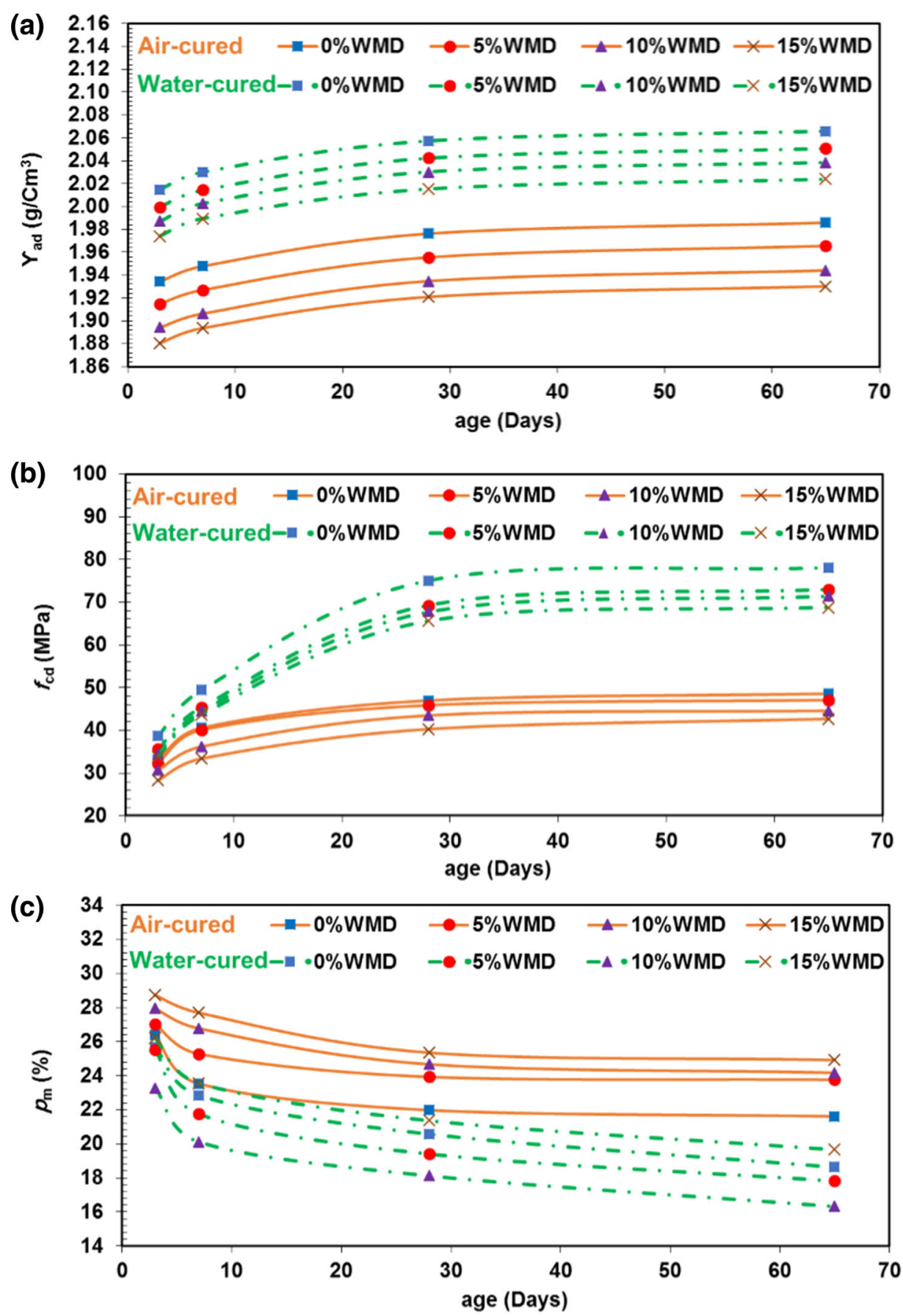

Fig. 4. The effect of curing conditions on the evolution of the properties of cement-based composites blended with waste marble dust (WMD) at different ages for: (a) apparent density $\left(\Upsilon_{\mathrm{ad}}\right)$; (b) compressive strength $\left(f_{\mathrm{cd}}\right)$; (c) porosity $\left(p_{\mathrm{m}}\right)$.

may be due to the substantial decrease in the clinker content of the mix. The consequence of the increase of WMD from 5 to $10 \%$ is a slight decrease in the porosity. In turn, a $15 \%$ level of WMD of the mass of the binder caused an increase of the porosity. These results cannot be compared with those found in Ref. 56.
In the case of air-cured conditions, the results show an increase of the porosity with a corresponding increase of the WMD content for all curing ages. This may be explained by the decrease in the volume of hydration products. Compared with the control cement-based composite, the increase of WMD from 5 to $15 \%$ caused an increase in the porosity. 
To analyze the microstructure of the cementbased composites with and without WMD, SEM analysis was used. The back-scattered electron (BSE) and energy-dispersive x-ray spectroscopy (EDX) images of the cement-based composites containing WMD at 28 days in different curing conditions are presented in Figs. 5 and 6, respectively.

For both curing conditions, Fig. 5 shows that the microstructure of the cement-based composites blended with WMD is different from that for the control composite. In addition (Fig. 6), the silicate hydrate (measured as $\mathrm{Si}$ ) showed a decrease with the increase of the WMD content of up to $15 \%$ of the mass of the binder. Moreover, the black particles shown in Fig. 6 mean that there is no Si. This decrease may be due to the lower $\mathrm{SiO}_{2}$ content in the WMD compared with the OPC.

By comparison, Fig. 5 also shows that the aircured cement-based composites presented a higher content of anhydrate products than those cured in water, which means that the water-cured cementbased composites have a higher hydration degree than that of the air-cured cement-based composites. In addition, all the compounds of the water-cured cement-based composites, compared with the aircured cement-based composites, were hydrated. This may be due to the water-evaporation rate, which causes an incomplete hydration process for the air-cured cement-based composites.

Furthermore, EDX was used to determine the chemical composition of the samples. Due to the small differences in chemical composition, the spectra seem similar (Fig. 7); however, the quantitative analysis showed significant changes (Table II). As Table II shows, the replacement of OPC with WMD of up to $15 \%$ increases the content of calcium hydrate $(\mathrm{Ca})$ because of the presence of calcite $\left(\mathrm{CaCO}_{3}\right)$ in the WMD. In addition, the content of aluminum hydrate (Al) and iron hydrate $(\mathrm{Fe})$ decreases because of the smaller content of aluminum oxide $\left(\mathrm{Al}_{2} \mathrm{O}_{3}\right)$ and ferric oxide $\left(\mathrm{Fe}_{2} \mathrm{O}_{3}\right)$ in the WMD. This can also be explained by the reaction of tricalcium aluminate (C3A) with calcite (CaCO3). ${ }^{27,32,37,41}$ Figure 7 and Table II also show that the increase of WMD of up to $15 \%$ of the mass of the binder decreases the silicate hydrate (measured as $\mathrm{Si}$ ) at all curing ages. This confirmed the observation of the Si on the EDX images. A sulfur peak is observed in Fig. 7, which confirms the formation of gypsum and ettringite, along with calcium silicate hydrate (C-S-H) and portlandite $\left(\mathrm{Ca}(\mathrm{OH})_{2}\right) \cdot{ }^{38} \mathrm{In}$ addition, the appearance of a potassium hydrate peak (K) can also be seen (Fig. 7) and can be observed in all the water-cured composites. This means that the air-cured composites lose the part of water needed to hydrate. The loss of this part led to an incomplete hydration process and an increase in the content of air voids. ${ }^{22}$

In both curing conditions, the incorporation of WMD of up to $10 \%$ of the mass of the binder as a cement replacement led to an increase of the calcium hydrate $(\mathrm{Ca})$ content. This may be due to the presence of $\mathrm{CaCO}_{3}$ in the WMD. In addition, the aluminum hydrate $(\mathrm{Al})$ and iron hydrate $(\mathrm{Fe})$ content in the composites showed a decrease, which may be due to the lower content of $\mathrm{Al}_{2} \mathrm{O}_{3}$ and $\mathrm{Fe}_{2} \mathrm{O}_{3}$ in the WMD. This can also be seen with the use of WMD at $15 \%$ of the mass of the binder. This led to a decrease of the Ca content in the composite and was probably caused by the incomplete hydration process as a result of the loss of some evaporated water.

In the case of the air-cured conditions (Fig. 7 and Table II), the increase of the percentage of $\mathrm{Al}$ and $\mathrm{Fe}$ hydrates in the specimens with $15 \% \mathrm{WMD}$ can be explained by the reaction of $\mathrm{C}_{3} \mathrm{~A}$ with $\mathrm{CaCO}_{3}$, which led to the formation of calcium carbo-aluminates (CCA) ${ }^{27,32,37,41}$ In addition, the $\mathrm{CaCO}_{3}$ reacts with tetracalcium-aluminoferrite and forms calcium carbo- aluminoferrites (CCAF). ${ }^{27,69}$

The obtained percentage of the portlandite $\left(\mathrm{Ca}(\mathrm{OH})_{2}\right)$ content in the composite with $10 \%$ WMD was higher than the percentage of the portlandite $\left(\mathrm{Ca}(\mathrm{OH})_{2}\right)$ content of the composite with $15 \%$ WMD. This is due to the higher percentage content of $\mathrm{Ca}$ hydrate present in the composite containing 10\% WMD compared with the percentage of $\mathrm{Ca}$ hydrate present in the cement-based composite containing 15\% WMD. The EDX confirmed these results and indicated that the content of $\mathrm{Ca}$ hydrate in the water-cured cement-based composite and air-cured cement-based composite containing $10 \% \mathrm{WMD}$ was higher than that present in the cement-based composite containing $15 \%$ WMD.

The increase of the WMD ratio decreases the calcium silicate hydrate (C-S-H) content in the cement-based composite, which is due to the increase of the portlandite $\left[\mathrm{Ca}(\mathrm{OH})_{2}\right]$ content and the decrease of silicate hydrate $(\mathrm{Si})$.

To characterize the phase structure of the cement-based composite with WMD at different curing conditions after 28 days of being cured in air or water, SEM-EDX analyses were used (Fig. 8).

The EDX analysis measured 50 points of each composite to create the plot of $\mathrm{Al} / \mathrm{Ca}$ as a function of $\mathrm{Si} / \mathrm{Ca}$, which allowed the composition of the C-S-H phase to be obtained. In this plot, the $\mathrm{Al} / \mathrm{Si}$ ratio of the C-S-H was determined by the slope of a line drawn through the points with the lowest $\mathrm{Al} / \mathrm{Ca}$ ratio and represents the mixed analyses of the portlandite $\left(\mathrm{Ca}(\mathrm{OH})_{2}\right)$ and C-S-H without aluminum iron monosulfate $(\mathrm{AFm})$ or ettringite. The measurements with lower $\mathrm{Si} / \mathrm{Ca}$ ratios also represent the mixed analyses of the C-S-H and portlandite. The bulk of data points along this line represents the range of the $\mathrm{Si} / \mathrm{Ca}$ ratios of the $\mathrm{C}-\mathrm{S}-\mathrm{H}^{70}$

The obtained results were characterized by a large dispersion, which requires the use of scattering indicators. In addition, the resulting distributions were asymmetrical. The arithmetic mean or standard deviation was not immune to outliers in the probe. Therefore, the interquartile range was 
Air-cured
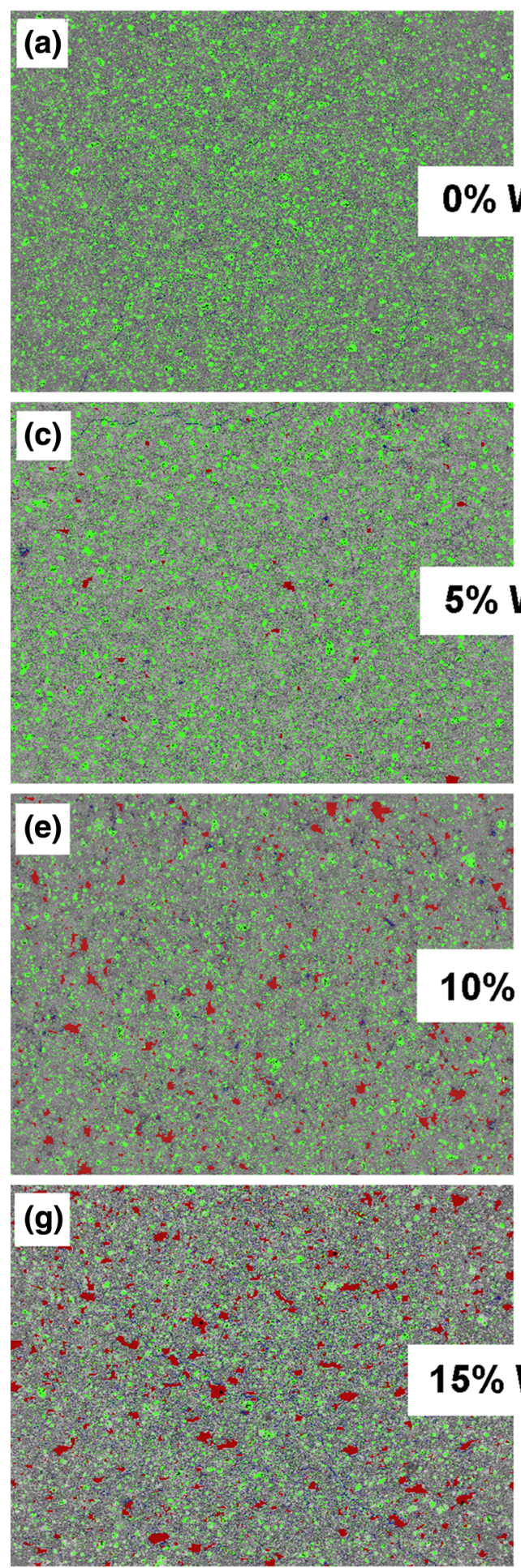

Water-cured

(b)
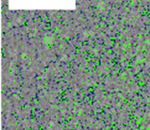

\section{\% WMD}

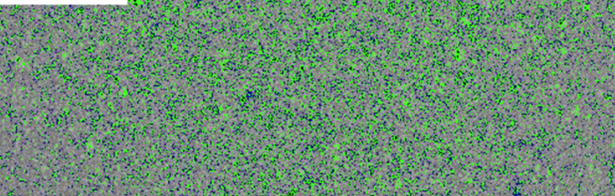

\section{(d)}

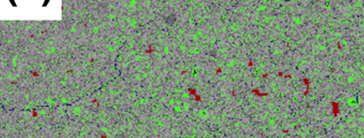

\section{WMD}
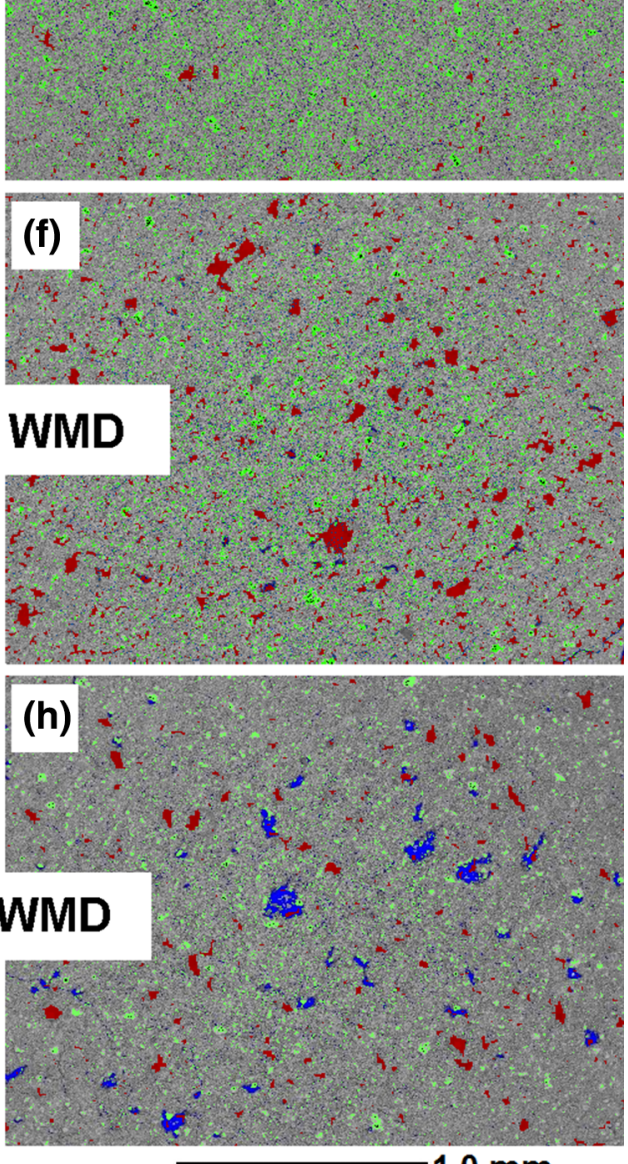

$1,0 \mathrm{~mm}$

Fig. 5. Back-scattered electron (BSE) images of cement-based composites with different waste marble dust (WMD) contents: (a) 0\% WMD cured in air; (b) 0\% WMD cured in water; (c) 5\% WMD cured in air; (d) 5\% WMD cured in water; (e) 10\% WMD cured in air; (f) 10\% WMD cured in water; (g) $15 \%$ WMD cured in air; $(\mathrm{h}) 15 \%$ WMD cured in water. $\mathrm{Ca}(\mathrm{OH})_{2}=$ portlandite (colored red); air voids (colored blue); anhydrate products (colored green) (Color figure online). 
Air-cured
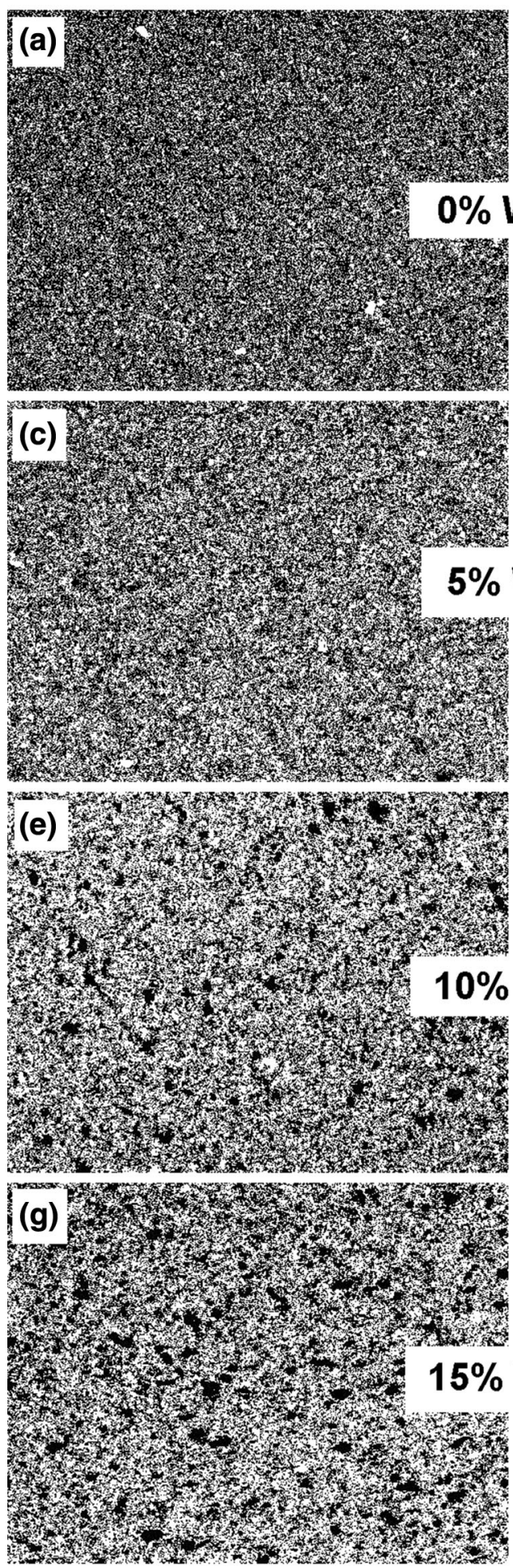

Water-cured
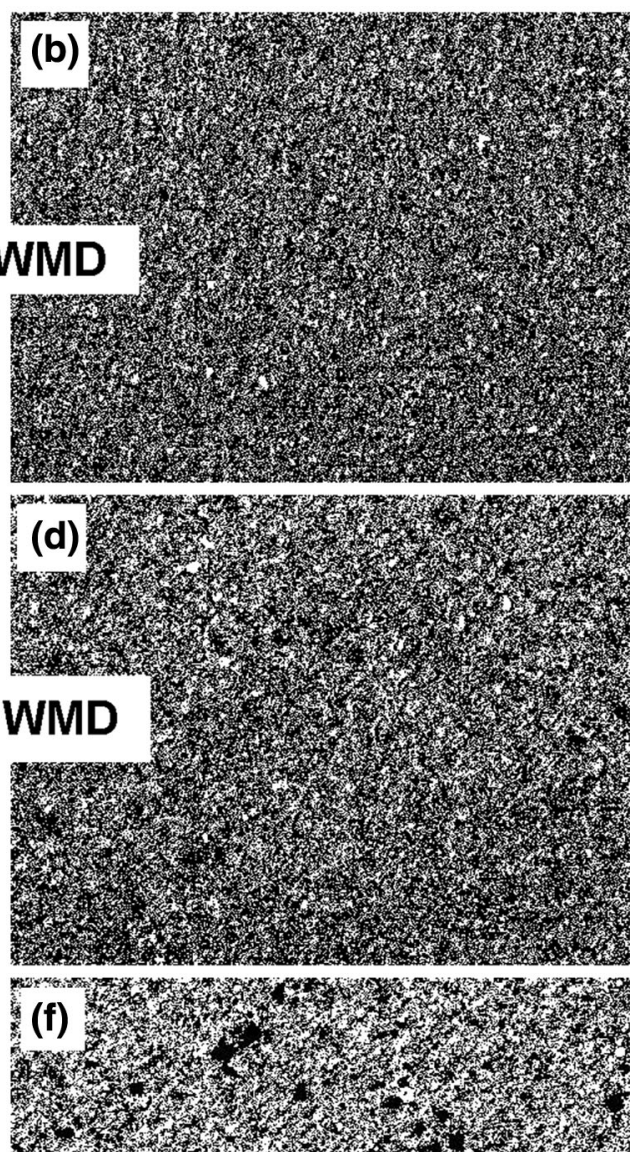

$10 \%$ WMD
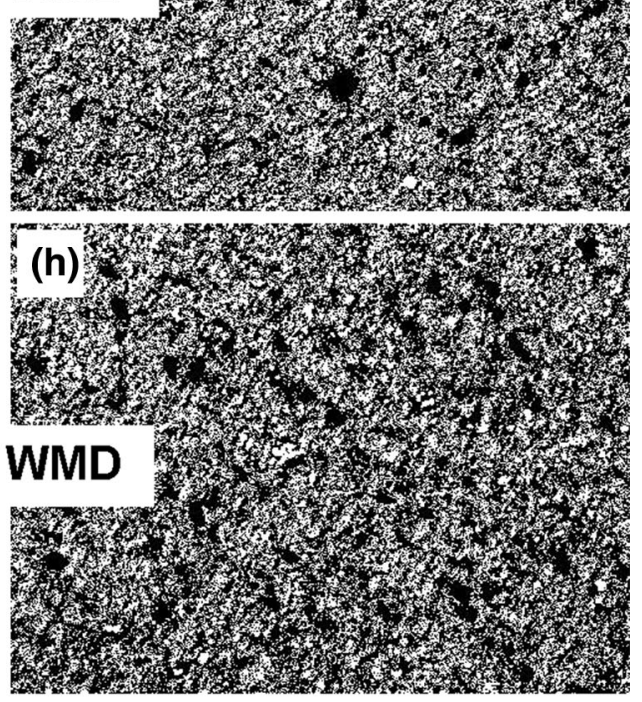

$1,0 \mathrm{~mm}$

Fig. 6. Si EDX mapping of cement-based composites with different waste marble dust (WMD) contents: (a) $0 \%$ WMD cured in air; (b) $0 \%$ WMD cured in water; (c) 5\% WMD cured in air; (d) 5\% WMD cured in water; (e) 10\% WMD cured in air; (f) 10\% WMD cured in water; (g) 15\% WMD cured in air; (h) $15 \%$ WMD cured in water (visible segregation increase as the function of WMD \%). 


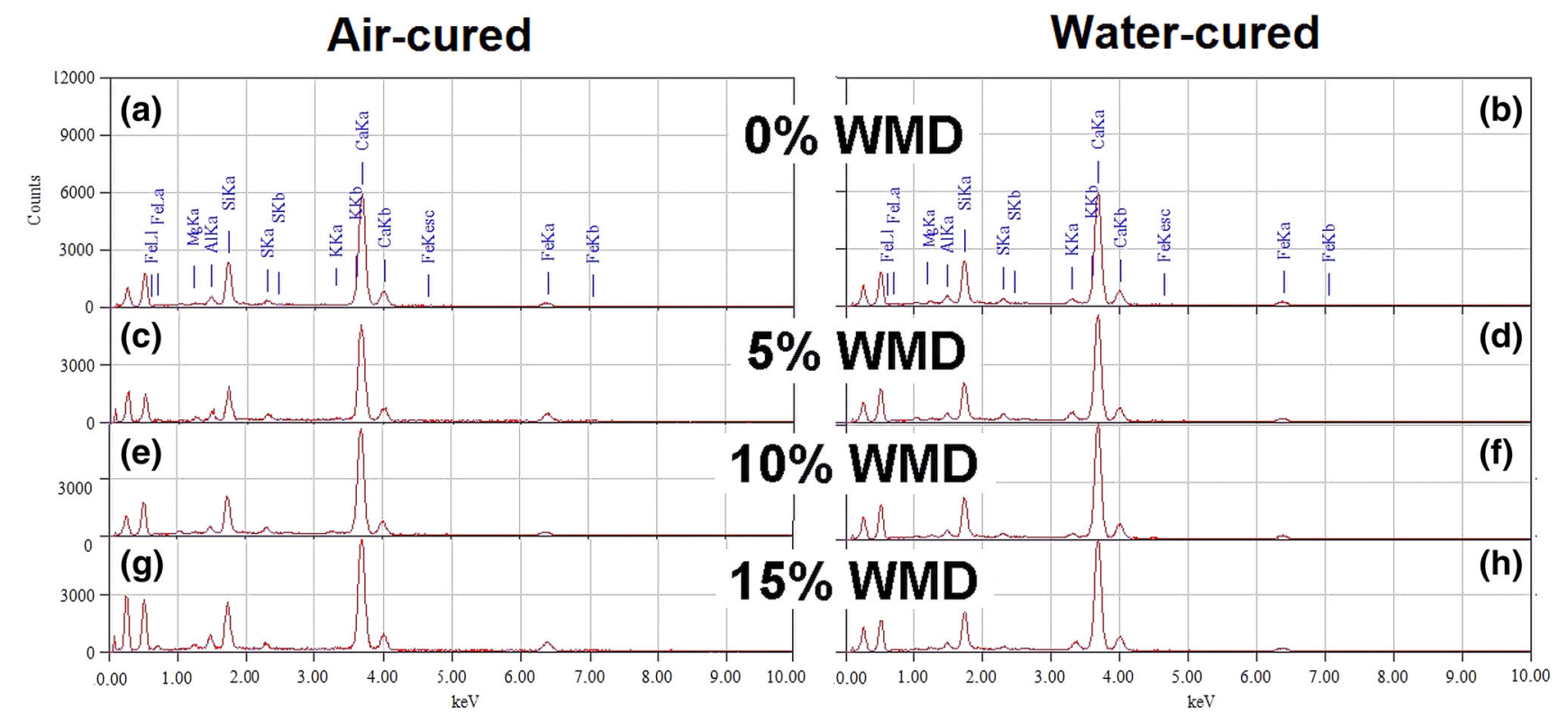

Fig. 7. Energy-dispersive x-ray spectroscopy (EDX) of cement-based composites replaced with different waste marble dust (WMD) contents: (a) 0\% WMD; (b) 0\% WMD cured in water; (c) 5\% WMD cured in air; (d) 5\% WMD cured in water; (e) 10\% WMD cured in air; (f) $10 \%$ WMD cured in water; (g) $15 \%$ WMD cured in air; (h) $15 \%$ WMD cured in water (results obtained with a $20-\mathrm{kV}$ accelerating voltage).

Table II. Chemical elements of hardened cement-based composite replaced with different WMD contents cured in air and in water-results obtained from EDX analysis

Element content (\% weight)

\begin{tabular}{|c|c|c|c|c|c|c|c|c|}
\hline \multirow[b]{2}{*}{ Chemical element } & \multicolumn{4}{|c|}{ Air cured (WMD content) } & \multicolumn{4}{|c|}{ Water cured (WMD content) } \\
\hline & $\mathbf{0}$ & 5 & 10 & 15 & $\mathbf{0}$ & 5 & 10 & 15 \\
\hline $\mathrm{O}$ & 49.77 & 51.26 & 50.63 & 51.56 & 48.77 & 48.85 & 48.90 & 49.25 \\
\hline $\mathrm{Ca}$ & 30.12 & 32.26 & 34.05 & 31.84 & 35.25 & 35.96 & 36.90 & 34.15 \\
\hline $\mathrm{Si}$ & 10.78 & 9.22 & 8.99 & 8.75 & 8.81 & 8.29 & 8.14 & 8.01 \\
\hline $\mathrm{Fe}$ & 4.92 & 3.52 & 3.05 & 3.87 & 2.65 & 2.65 & 2.60 & 2.57 \\
\hline $\mathrm{Al}$ & 2.72 & 2.12 & 1.76 & 2.35 & 1.68 & 1.63 & 1.54 & 1.55 \\
\hline $\mathrm{Mg}$ & 0.94 & 0.87 & 0.86 & 0.88 & 0.45 & 0.59 & 0.48 & 0.55 \\
\hline $\mathrm{S}^{\circ}$ & 0.75 & 0.75 & 0.66 & 0.75 & 0.97 & 0.79 & 0.65 & 1.44 \\
\hline K & - & - & - & - & 1.42 & 1.24 & 0.79 & 2.48 \\
\hline Total & 100 & 100 & 100 & 100 & 100 & 100 & 100 & 100 \\
\hline
\end{tabular}

used, which is based on the measurement of dispersion of the central part of the probe. The plots showed the median of both curing conditions and for each content of WMD. The values of the lower and upper quartiles for $\mathrm{Al} / \mathrm{Si}$ and $\mathrm{Si} / \mathrm{Ca}$ were determined (Fig. 8). After analysis of the comparison of the medians and interquartile range of the $\mathrm{Si} / \mathrm{Ca}$ and $\mathrm{Al} / \mathrm{Ca}$ atomic ratio densities, depending on the WMD content for both curing conditions, it is visible that the concentration of WMD increases, the $\mathrm{Si} / \mathrm{Ca}$ ratio decreases, and the values obtained for watercuring samples always revealed lower values. Samples containing $0 \%$ and 15\% WMD showed the highest dispersion of both curing conditions. The composites containing 5\% WMD revealed the lowest dispersion, and the sample containing 10\% WMD showed a slightly higher interquartile range. The $\mathrm{Al} / \mathrm{Ca}$ atomic ratios showed a similar dispersion, whereas the $15 \%$ WMD sample was characterized by a decidedly higher dispersion of the probe. Samples of 5\% and 10\% WMD for both curing conditions again revealed the smallest interquartile range. The median values of the $\mathrm{Al} / \mathrm{Ca}$ atomic ratios of the 5\% and 10\% WMD samples were 0.065 and 0.070 for the air-curing condition and 0.051 for water curing. For the air-cured samples of $0 \%$ and $15 \% \mathrm{WMD}$, an increase in the $\mathrm{Al} / \mathrm{Ca}$ atomic ratio to 0.087 and 0.10 was observed. The water-cured 

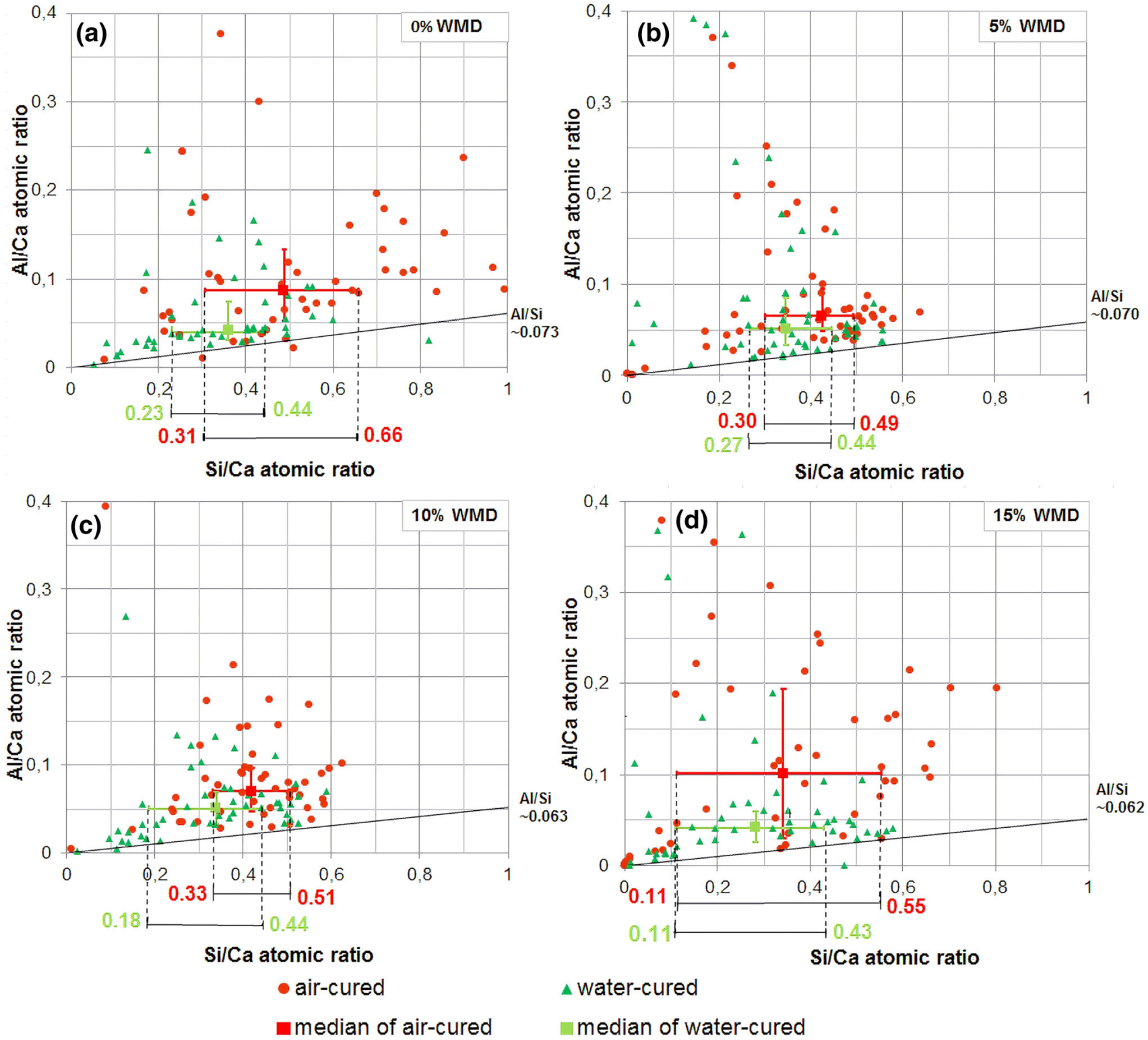

\section{$\triangle$ water-cured \\ median of water-cured}

Fig. 8. Plot of $\mathrm{Al} / \mathrm{Ca}$ as a function of the $\mathrm{Si} / \mathrm{Ca}$ atomic ratios of the EDX-measurements of the air- and water-cured cement-based composites replaced with different waste marble dust (WMD) contents: (a) 0\% WMD; (b) 5\% WMD; (c) 10\% WMD; (d) 15\% WMD (results obtained with a 20$\mathrm{kV}$ accelerating voltage).

composites showed an inverse tendency-the $0 \%$ and $15 \% \mathrm{WMD}$ samples showed a decrease in the $\mathrm{Al} /$ $\mathrm{Ca}$ atomic ratio to 0.043 and 0.041 .

In the case of water-curing conditions, the composites containing $0 \%, 5 \%$ and $10 \%$ WMD showed a similar range of bulk points of the $\mathrm{Si} / \mathrm{Ca}$ ratio of the C-S-H, which ranged from 0.18 to 0.44 . As for the composites with $15 \% \mathrm{WMD}$, the bulk points of the $\mathrm{Si} / \mathrm{Ca}$ ratio of the C-S-H ranged from 0.11 to 0.43 , respectively. The obtained $\mathrm{Si} / \mathrm{Ca}$ ratios, compared with the air-cured samples, were shifted to lower values. Only for the composite containing $15 \%$ WMD were these values similar.
The $\mathrm{Al} / \mathrm{Si}$ ratio of the $\mathrm{C}-\mathrm{S}-\mathrm{H}$ was affected by the use of WMD from $0 \%$ to $15 \%$ and decreased from 0.073 to 0.062 . This was due to the lower $\mathrm{Al}$ and $\mathrm{Si}$ present in the WMD.

The control cement-based composite has a large range of bulk points of the $\mathrm{Si} / \mathrm{Ca}$ ratio of the $\mathrm{C}-\mathrm{S}-\mathrm{H}$, from 0.30 to 0.66 . In the case of the cement-based composite containing WMD in amounts of 5\% and $10 \%$, the results showed a similar range of bulk points of the $\mathrm{Si} / \mathrm{Ca}$ ratio of the $\mathrm{C}-\mathrm{S}-\mathrm{H}$, from 0.30 to 0.51 . As for the composites with $15 \%$ WMD, the bulk points of the $\mathrm{Si} / \mathrm{Ca}$ ratio of the C-S-H ranged from 0.11 to 0.55 . In the case of composites containing $0 \%$ 
and $15 \% \mathrm{WMD}$, there was a large dispersion of points. This means that there is a possibility to obtain a big or small content of C-S-H, and this is undesirable.

In the case of both curing conditions, the presence of lower $\mathrm{Si} / \mathrm{Ca}$ ratios in the cement-based composite containing WMD is due to the additional Ca provided by the WMD, which is incorporated in the C$\mathrm{S}-\mathrm{H}$ microstructure. It is also due to a lower $\mathrm{Si}$ presence in the WMD. The Al/Si ratio of the C-S-H is almost similar in both curing conditions. The $\mathrm{Al} /$ Si ratio was affected by the use of WMD from $0 \%$ to $15 \%$ and decreased from 0.073 to 0.062 . This is due to the lower content of $\mathrm{Al}$ and $\mathrm{Si}$ present in the WMD.

Finally, it can be stated that the C-S-H content is not significantly affected by the use of WMD in an amount of up to $10 \%$ when the composites are cured in water. The decrease of compressive strength is not due to the C-S-H content, but is down to the decrease of apparent density. In turn, for the aircured composites, the C-S-H content was affected by the use of WMD in an amount up to $15 \%$. The decrease of compressive strength is due to the water-evaporation rate, the presence of low humidity in air, the C-S-H content and also the decrease of apparent density.

The parameters, such as compressive strength, apparent density and porosity, proved that there is a dependence between them.

\section{CONCLUSION}

The goal of the presented study was to investigate the effect of curing conditions on the properties of a cement-based composite blended with waste marble dust (WMD). Based on the executed experiments, the following conclusions can be drawn:

- the water-curing conditions resulted in higher compressive strength of cement paste blended with WMD compared with the air curing conditions. It was also observed that the compressive strength increases with an increase in the duration of water curing,

- the porosity of cement paste increased for the air-curing conditions and decreased for the water-curing conditions,

- the SEM-EDX analysis indicated that the use of WMD led to an increase in the Ca content and a decrease in the $\mathrm{Si}$ content for both curing conditions. It also caused a slight decrease of the C-S-H content in the cement pastes,

- the plot of $\mathrm{Al} / \mathrm{Ca}$ versus $\mathrm{Si} / \mathrm{Ca}$ of water-cured cement paste indicates that the use of WMD in an amount up to $10 \%$ has no effect on the C-S-H products.

To sum up, the results indicate the possibility of using WMD as a cement replacement in an amount of up to $10 \%$ of the mass of the binder when composites are cured in water.

\section{OPEN ACCESS}

This article is distributed under the terms of the Creative Commons Attribution 4.0 International License (http://creativecommons.org/licenses/by/4.0/), which permits unrestricted use, distribution, and reproduction in any medium, provided you give appropriate credit to the original author(s) and the source, provide a link to the Creative Commons license, and indicate if changes were made.

\section{REFERENCES}

1. N. Fonseca, J. De Brito, and L. Evangelista, Cem. Concr. Compos. 33, 637 (2011).

2. B. Ozer and M.H. Ozkul, Cem. Concr. Res. 34, 13 (2004).

3. R.V. Silva, J. De Brito, and N. Saikia, Cem. Concr. Compos. 35,23 (2013).

4. A.A. Ramezanianpour and V.M. Malhotra, Cem. Concr. Compos. 17, 125 (1995).

5. G.L. Golewski, Compos. Struct. 185, 105 (2018).

6. H. Toutanji, N. Delatte, S. Aggoun, R. Duval, and A. Danson, Cem. Concr. Res. 34, 311 (2004).

7. A.F. Bingöl and I. Tohumcu, Mater. Des. 51, 12 (2013).

8. C.S. Poon, Y.L. Wong, and L. Lam, Constr. Build. Mater. 11, 383 (1997).

9. C.M. Aldea, F. Young, K. Wang, and S.P. Shah, Cem. Concr. Res. 30, 465 (2000).

10. H. Yazıc1, Build. Environ. 42, 2083 (2007).

11. A. Allahverdi, S. Pilehvar, and M. Mahinroosta, Powder Technol. 288, 132 (2016).

12. L. Xu, K. Wu, C. Rößler, P. Wang, and H.M. Ludwig, Cem. Concr. Compos. 80, 298 (2017).

13. M. Velay-Lizancos, J.L. Perez-Ordoñez, I. Martinez-Lage, and P. Vazquez-Burgo, Constr. Build. Mater. 144, 195 (2017).

14. L.Y. Gómez-Zamorano and J.I. Escalante-García, Cem. Concr. Compos. 32, 603 (2010).

15. B. Ilić, V. Radonjanin, M. Malešev, M. Zdujić, and A. Mitrović, Constr. Build. Mater. 133, 243 (2017).

16. H. Zhao, W. Sun, X. Wu, and B. Gao, Mater. Des. 35, 194 (2012).

17. G.L. Golewski, Compos. Struct. 200, 515 (2018).

18. B.J. Zhan, D.X. Xuan, C.S. Poon, and C.J. Shi, Cem. Concr. Compos. 71, 122 (2016).

19. M. Velay-Lizancos, J. Martinez-Lage, M. Azenha, and P. Vázquez-Burgo, Constr. Build. Mater. 124, 276 (2016).

20. C.D. Atiş, Cem. Concr. Res. 35, 1112 (2005).

21. M. Ibrahim, M. Shameem, M. Al-Mehthel, and M. Maslehuddin, Cem. Concr. Compos. 41, 60 (2013).

22. P. Termkhajornkit, T. Nawa, and K. Kurumisawa, Cem. Concr. Compos. 28, 781 (2006).

23. M. Salhi, M. Ghrici, A. Li, and T. Bilir, Adv. Concr. Constr. 5, 359 (2017).

24. P. Rizzo, A. Nasrollahi, W. Deng, and J.M. Vandenbossche, Appl. Sci. 6, 104 (2016).

25. M. Uysal and K. Yilmaz, Cem. Concr. Compos. 33, 771 (2011).

26. M. Safiuddin, M.Z. Jumaat, M.A. Salam, M.S.S. Islam, and R. Hashim, Int. J. Phys. Sci. 5, 1952 (2010).

27. N. Toubal Seghir, M. Mellas, Ł. Sadowski, and A. Żak, J. Cleaner Prod. 183, 858 (2018).

28. A. Talah, F. Kharchi, and R. Chaid, Procedia Eng. 114, 685 (2015).

29. D.K. Ashish, S.K. Verma, R. Kumar, and N. Sharma, Adv. Concr. Constr. 4, 145 (2016).

30. V.M. Sounthararajan and A. Sivakumar, ARPN J. Eng. Appl. Sci. 8, 260 (2013).

31. K. Vardhan, S. Goyal, R. Siddique, and M. Singh, Constr. Build. Mater. 96, 615 (2015).

32. A. Ergün, Constr. Build. Mater. 25, 806 (2011).

33. O. Keleştemur, E. Arıcı, S. Yıldız, and B. Gökçer, Constr. Build. Mater. 60, 17 (2014). 
34. B. Demirel, Int. J. Phys. Sci. 5, 1372 (2010).

35. B. Ercikdi, G. Külekci, and T. Yılmaz, Constr. Build. Mater. 93, 573 (2015).

36. A.M. Zeyad, M.A.M. Johari, B.A. Tayeh, and M.O. Yusuf, $J$ Cleaner Prod. 144, 511 (2017).

37. H.S. Arel, J Cleaner Prod. 131, 179 (2016).

38. D.M. Sadek, M.M. El-Attar, and H.A. Ali, J Cleaner Prod. 121,19 (2016).

39. A. Boukhelkhal, L. Azzouz, A.S.E. Belaïdi, and B. Benabed, J. Adhes. Sci. Technol. 30, 2405 (2016).

40. H. Binici, T. Shah, O. Aksogan, and H. Kaplan, J. Mater. Process. Technol. 208, 299 (2008).

41. G.C. Ulubeyli and R. Artir, Proc. Soc Behav. Sci. 195, 2181 (2015).

42. V. Corinaldesi, G. Moriconi, and T.R. Naik, Constr. Build. Mater. 24, 113 (2010).

43. A. Khodabakhshian, J. De Brito, M. Ghalehnovi, and E.A. Shamsabadi, Constr. Build. Mater. 169, 237 (2018).

44. R.A. Hamza, S. El-Haggar, and S. Khedr, Int. J. Biosci. Biochem. Bioinf. 1, 286 (2011).

45. M. Gesoğlu, E. Güneyisi, M.E. Kocabağ, V. Bayram, and K. Mermerdaş, Constr. Build. Mater. 37, 160 (2012).

46. K.E. Alyamac, E. Ghafari, and R. Ince, J Cleaner Prod. 144, $192(2017)$

47. A.S.E. Belaidi, S. Kenai, E.H. Kadri, H. Soualhi, and B. Benchaâ, J. Adhes. Sci. Technol. 30, 247 (2016).

48. A.S.E. Belaidi, L. Azzouz, E. Kadri, and S. Kenai, Constr. Build. Mater. 31, 251 (2012).

49. M. Uysal, Adv. Civ. Eng., 8093576, 2018.

50. J.S. Buyuksagis, T. Uygunoglu, and E. Tatar, Constr. Build. Mater. 154, 734 (2017).

51. M. Singh, A. Srivastava, and D. Bhunia, Constr. Build. Mater. 134, 471 (2017).

52. H.A. Mohamadien, Int. J. Civ. Struct. Eng. 3, 418 (2012).

53. A.A. Aliabdo, A.E.M.A. Elmoaty, and E.M. Auda, Constr. Build. Mater. 50, 28 (2014).
54. R. Chaid, A. Perrot, and Y. Ghernouti, 5th Int. Conf. Env. Sci. Eng. 83, 6 (2015).

55. F. Colangelo, G. Roviello, L. Ricciotti, V. Ferrándiz-Mas, F. Messina, C. Ferone, and C.R. Cheeseman, Cem. Concr. Compos. 86, 266 (2018).

56. A.O. Mashaly, B.A. El-Kaliouby, B.N. Shalaby, A.M. ElGohary, and M.A. Rashwan, J Cleaner Prod. 112, 731 (2016).

57. http://www.biskriaciment-dz.com/Nos-Produits.aspx.

58. https://www.enamarbre.dz.

59. C. Costa, M. Monteiro, B. Rangel, and F.J.L. Alves, Proc. Instit. Mech. Eng. Part L: J Mater. Des. Appl. 231, 247 (2017).

60. P.C. Hewlett, Lea's Chemistry of Cement and Concrete (Boston: Elsevier Butterworth-Heinemann, 2003).

61. M.S. Kirgiz, Mech. Mater. 92, 223 (2016).

62. ASTM, C. 109/C 109 M-99, 1999. Standard test method for the compressive strength of hydraulic cement mortars (using 2-in. or [50-mm] cube specimens), annual book of ASTM, standards, 4.

63. J.E. Ash, M.G. Hall, J.I. Langford, and M. Mellas, Cem. Concr. Res. 23, 399 (1993).

64. L.J. Parrott, Cem. Concr. Res. 11, 651 (1981).

65. EN 196-3:2005. Methods of testing cement: determination of setting time and soundness.

66. O. Gencel, C. Ozel, F. Koksal, E. Erdogmus, G. MartínezBarrera, and W. Brostow, J Cleaner Prod. 21, 62 (2012).

67. R. Rodrigues, J. De Brito, and M. Sardinha, Constr. Build. Mater. 77, 349 (2015).

68. M.S. Meddah, M.C. Lmbachiya, and R.K. Dhir, Constr. Build. Mater. 58, 193 (2014).

69. K.D. Ingram and K.E. Daugherty, Cem. Concr. Compos. 13, 165 (1991).

70. F. Deschner, B. Winnefeld, S. Lothenbach, P. Seufert, S. Schwesig, S. Dittrich, F. Goetz-Neunhoeffer, and J. Neubauer, Cem. Concr. Res. 42, 1389 (2012). 